\title{
Entrevista
}

\section{Dmitry A. Leontiev}

\section{Perspectivas e tensões no âmbito das psicologias histórico-culturais, com foco nas contribuições de Alexei N. Leontiev ${ }^{1}$}

\author{
Andréa Maturano Longarezi ${ }^{2}$ \\ Roberto Váldes Puentes ${ }^{3}$
}

\section{Apresentação}

Dmitry Alekseevich Leontiev, neto de Alexis Nikolaevich Leontiev (19031979) e filho de Alexey Alekseevich Leontiev (1936-2004), é um dos psicólogos russos mais importantes da atualidade.

Nasceu em Moscou, em julho de 1960, e formou-se em Psicologia pela Universidade Estatal de Moscou. É especialista em várias áreas do conhecimento psicológico, especialmente, em psicologia da personalidade e da motivação, em teoria e história da psicologia, bem como em psicodiagnóstico.

1 Entrevista concedida por Dmitry Alekseevich Leontiev aos organizadores do II Colóquio Internacional Ensino Desenvolvimental: vida, pensamento e obra dos principais representantes russos, realizado em maio de 2014, na Universidade Federal de Uberlândia, em Uberlândia/MG/BR. A entrevista contou com a tradução simultânea e transcrição, do russo para o português, realizadas por George Yurievitch Ribeiro e Regina Reptton Dias, respectivamente, e a revisão técnica de Andréa Maturano Longarezi e Roberto Váldes Puentes.

2 Doutora em Educação. Docente, vinculada à Faculdade de Educação, nos cursos de licenciatura e no Programa de Pós-graduação em Educação da Universidade Federal de Uberlândia, PPFED/FACED/UFU. ORCID: https://orcid.org/0000-0002-5651-9333. E-mail: andrea.longarezi@gmail.com.

${ }^{3}$ Doutor em Educação. Docente dos cursos de licenciatura e do Programa de Pós-graduação em Educação da Universidade Federal de Uberlândia, PPGED/FACED/UFU. ORCID: https://orcid.org/0000-0001-8936-9362. E-mail: robertovaldespuentes@gmail.com. 
Figura 1: Dmitry A. Leontiev durante o II Colóquio Internacional Ensino Desenvolvimental: vida, pensamento e obra dos principais representantes russos - maio de 2014, Uberlândia/Brasil.

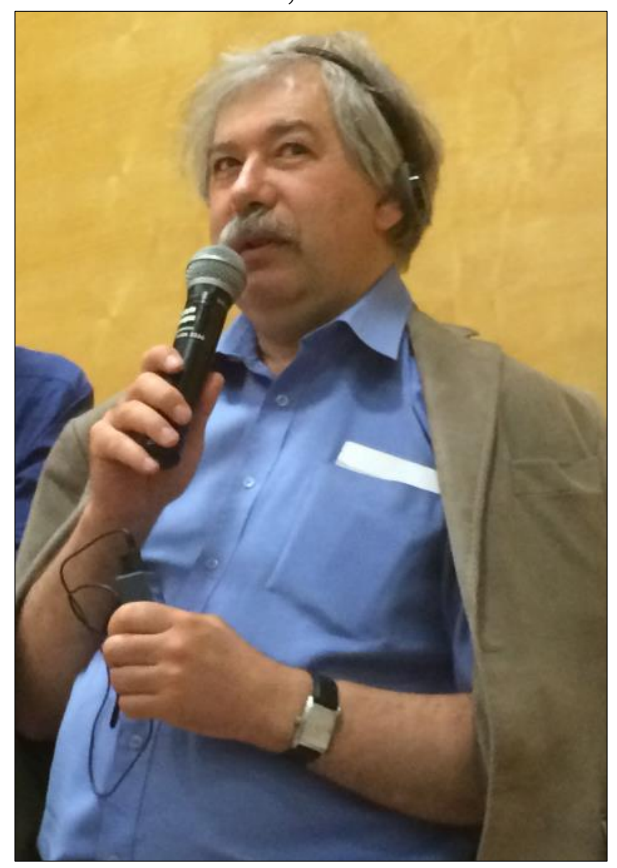

Fonte: Arquivo do GEPEDI.

Doutor em Psicologia e Chefe do Laboratório Internacional de Psicologia Positiva da Personalidade e da Motivação, atua como docente da Faculdade de Psicologia da Universidade Estatal M. V. Lomonosov, de Moscou, e da Universidade Psicológica e Pedagógica da Cidade de Moscou.

Possui uma ampla produção científica e acadêmica que supera os 600 trabalhos entre artigos, capítulos e livros completos. Pela sua extensa obra, tem recebido diferentes prêmios nacionais e internacionais.

Dmitry A. Leontiev, esteve no Brasil, a convite do GEPEDI - Grupo de Estudos e Pesquisas em Didática Desenvolvimental e Profissionalização Docente, para apresentar o texto que elaborou sobre a vida, o pensamento e a obra de seu pai Alexey Alekseevich Leontiev, durante o II Colóquio Internacional Ensino Desenvolvimental: vida, pensamento e obra dos principais representantes russos, realizado em maio de 2014, em Uberlândia/ Minas Gerais / Brasil, publicado em livro homônimo (LEONTIEV, 2015 [2017]); ocasião em que se deu a presente entrevista. 


\section{A entrevista}

ANDRÉA M. LONGAREZI e ROBERTO V. PUENTES: A. N. Leontiev é um dos psicólogos do período soviético mais respeitado no Brasil e se constitui uma importante referência para os pesquisadores, especialmente, por suas contribuições à Psicologia Histórico-Cultural da Atividade (LONGAREZI, 2019a; 2019b; 2020a; 2020b; LONGAREZI; FRANCO, 2013; 2015; PUENTES, 2017; PUENTES; LONGAREZI, 2017a, 2017b). No concernente à relação da atividade externa e atividade interna, nota-se, pelas obras a que a academia brasileira teve acesso (LEONTIEV, 1978; 1983; 1986a; 1986b; 1986c; 1989a; 1989b;2001; 2006; 2017; entre outras), que A. N. Leontiev designa à atividade externa, gênese da consciência. Gostaríamos de ouvir sua compreensão a respeito da relação do externo-interno na constituição da psique, a partir da perspectiva defendida por ele.

DMITRY A. LEONTIEV: A. N. Leontiev era um pouco diferente. Em seus trabalhos, no final da década de 1930, mostra um aspecto, aparentemente simples, mas que na verdade é bastante complexo. Demonstra que não existe uma fronteira, um limite tão bem definido entre o externo e o interno e, ainda, que,para a psicologia, não é tão preponderante o que liga o externo e o interno na atividade. O principal, na atividade, é o processo que liga o homem ao mundo; por isso, não pode existir uma fronteira determinante entre o externo e o interno. A. N. Leontiev sempre mostrou que o processo de atividade tem vários elos; parte desses elos são internos e parte externos. O processo de desenvolvimento, por exemplo, ou os processos que eram externos, aos poucos passam a ser internos; contudo, é preciso, para sua correção, que essas funções psíquicas se tornem novamente externas.

Muitas vezes, nem se fala da psicologia histórico-cultural e da psicologia da atividade. $\mathrm{Eu}$, como muitos, considero-as como algo que se juntam, chamam essas psicologias de psicologia não clássica. Esse tema quem criou foi Daniil B. Elkonin. Existe uma série de discussões sobre como entender essa não classicidade, esse não clássico. 
Para mim, o principal aspecto que faz dessas psicologias histórico-culturais e da atividade, serem não clássicas, seria essa não definição de fronteiras. Sempre está se falando de transformações do externo para o interno e, ao contrário, do interno para o externo. E o principal, como dizia A. N. Leontiev, é a diferença, o antagonismo não entre o externo e o interno, mas sobre a imagem e o processo, a imagem seria algo estável, uma estrutura mais estável e o processo não. Em um artigo meu (LEONTIEV, 2005), publicado em inglês, discorro sobre isso, de forma mais detalhada e consistente.

Ele mesmo escrevia isso nas suas obras de uma forma bastante clara, o interno facilmente vira externo e vice-versa. Essa não é uma fronteira estável. O próprio conceito de atividade é algo que, justamente, supera sempre essa fronteira. As reações (tanto os estímulos quanto as reações) estão fora, são externas, a atração e o organismo psicodinâmico estão todos dentro. Os processos primitivos também são internos, e as atividades estão onde? Elas não podem ser localizadas, especificamente, em um ou outro desses lugares.

Figura 2: Registro da entrevista, concedida por Dmitry A. Leontiev no dia 06.05.2014. (da esquerda para direita: Roberto V. Puentes, Andréa M. Longarezi, Dmitry A. Leontiev e George Y. Ribeiro - tradutor).

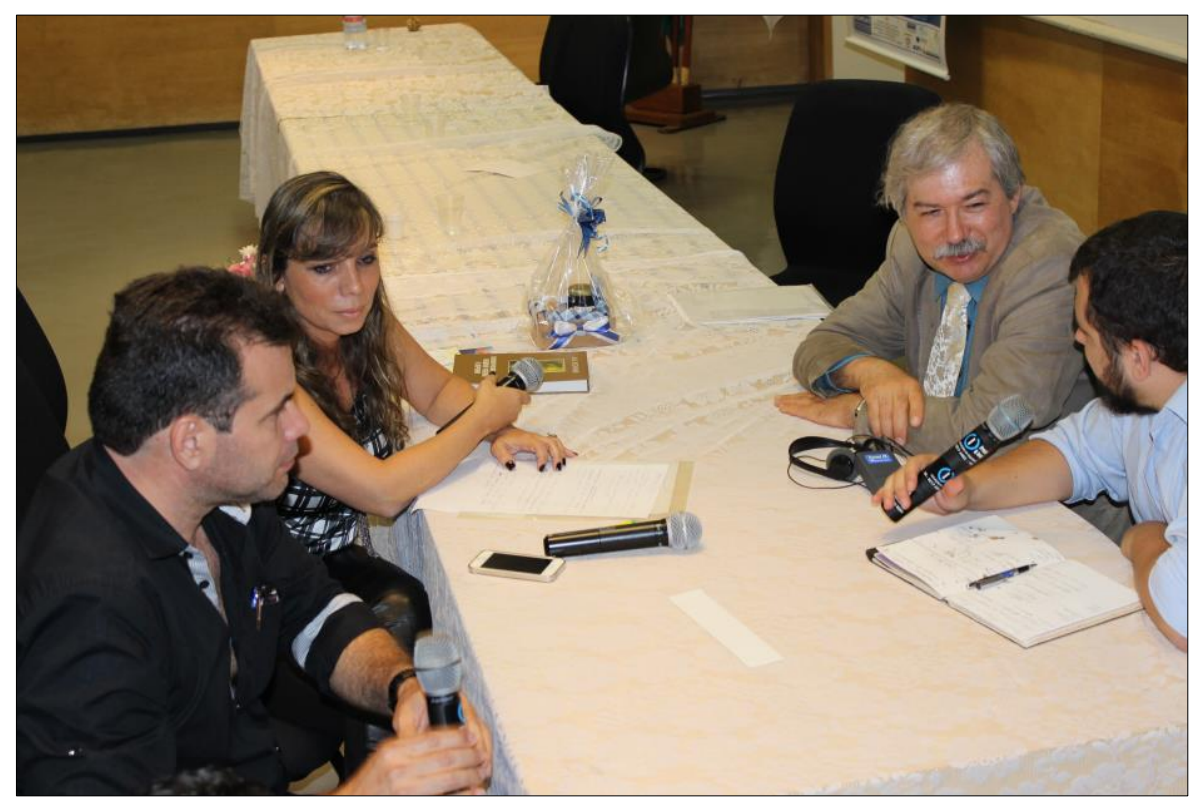

Fonte: Arquivo do GEPEDI. 
ANDRÉA M. LONGAREZI e ROBERTO V. PUENTES: Tanto S. L. Rubinstein, quanto de L. S. Vigotski concedem à psique, em momentos específicos de sua obra, um caráter ativo e gerador e enfatizam a capacidade da psique de produzir a realidade social. Como compreende isso no pensamento de A. N. Leontiev?

DMITRY A. LEONTIEV: Para A. N. Leontiev, a psique e a personalidade são coisas completamente diferentes; considera a personalidade como uma dimensão totalmente fora do psíquico. E a psique, a partir de todas as suas pesquisas, se manifesta como algo coativo, e não reativo. Começando por seu estudo de doutorado sobre percepção, onde formava a sensibilidade para perceber luz na ponta dos dedos, ele só comprovou que isso se desenvolve caso exista uma atividade, uma busca ativa, uma ação de procura, se você estiver mexendo com a mão. Se deixar a mão passiva não consegue criar essa sensibilidade, ela só surge através de uma busca ativa. Todas as outras experiências sobre, por exemplo, audição de sons, também revelam que são altamente necessários alguns processos motores ativos. Acho que não procede atribuir à A. N. Leontiev a passividade da psique. Ele utilizava a ideia de reflexo, da reflexividade, que era um construto filosófico obrigatório que não poderia desprezar. Mas, ele repensou, reformou esse conceito nas suas últimas obras, nas quais não fala mais de reflexo, passa a falar de criatividade.

S. L. Rubinstein, por sua vez, foi um filosofo impressionante, mas ele não era psicólogo, era filósofo e trabalhava como psicólogo. Foram publicadas, recentemente, algumas cartas de S. L. Rubinstein, dos últimos anos dele, em que coloca de maneira bastante irônica, que, embora não gostasse tanto de psicologia, tinha passado sua vida inteira ocupando-se dela. Em minha opinião, S. L. Rubinstein era um grande filósofo, mas um psicólogo relativamente médio. E os trabalhos de S. L. Rubinstein são bastante profundos, bem escritos, mas quando falava de atividade, de que a psique é ativa, ele falava isso no âmbito da filosofia. A. N. Leontiev, ao contrário, realizou esse lado ativo da psique em experimentos concretos. 
ANDRÉA M. LONGAREZI E ROBERTO V. PUENTES: Como A. N. Leontiev entende o potencial criativo, autônomo e a subjetividade no homem? Nesse sentido, como se constitui a personalidade sobre a base da teoria da atividade?

DMITRY A. LEONTIEV: São várias perguntas, vou me focar em uma delas. A. N. Leontiev utilizou o termo criatividade para expressar o conceito de imaginação. Ele se interessava pelo estudo da imaginação, entendia a importância desse problema, mas nunca o abordou. Sobre criatividade existiram trabalhos na psicologia da arte e na psicologia da criatividade artística, da criação artística. No tocante a esse assunto, o principal problema que ele enfocou tratava do problema das imagens, da visão do mundo, da imagem do mundo. E todos os processos cognitivos estariam, justamente, a serviço da criação dessa imagem, essa seria considerada a única do mundo, então, uma pré-construção dessa imagem. Ele queria escrever um livro sobre isso, mas não teve tempo, um dos últimos conceitos que ele queria trabalhar era o de imaginação. Mas, na década de 1970, muitos de seus alunos realizaram pesquisas e experimentos onde essas suas teorias foram postas à prova.

E, nesse contexto, ele avaliava a percepção e o processo cognitivo, não do ponto de vista que eram...; que se partia do mais elementar para aquilo cada vez mais complexo, mas, ao contrário, de que a imagem do mundo sempre existe, desde o início e todos os processos de percepção, pontuais ou não, sempre vão se complementando dessa imagem já existente. Na verdade, o que acontece ali nesse importante processo é que se começa verificar, que a nova percepção sempre se relaciona às anteriores. Ocorre um processo de acordo com o que já existe, porém, com uma visão mais ampla. Eram ideias muito novas, comprovadas por experimentos bastante bonitos, mas ele não conseguiu fazer depois a generalização.

ANDRÉA M. LONGAREZI E ROBERTO V. PUENTES: Na produção da psicologia soviética da época se constituíram, pelo menos, duas linhas, uma com foco na comunicação como a mediadora do homem com o mundo e, a outra, 
compreendendo essa mediação pela atividade. Como percebe essa tensão teórica na qual A. N. Leontiev estava diretamente envolvido?

DMITRY A. LEONTIEV: Quanto ao problema da comunicação, sei que alguns autores tiveram discussões nesse campo da comunicação e da atividade; alguns argumentavam que a comunicação era um tipo de atividade e, outros, ao contrário, diziam que era algo fora da atividade e altamente particular. Mas, ao meu avô, muitas vezes atribuíram coisas falsas, que ele nunca proferiu e levavam até níveis quase absurdos.

Eu escrevi um artigo, inclusive traduzido para o inglês (LEONTIEV, 1992), onde tentei retirar essa tensão da discussão sobre se a comunicação seria um tipo de atividade ou um processo independente. Foi escrito no contexto da pedagogia da cooperação e se chamava Atividade conjunta, comunicação e interação. Essa ideia de atividade conjunta transcende, justamente, uma compreensão de diferença entre a "comunicação como atividade" e a "comunicação como algo independente".

Figura 3: Roberto V. Puentes, Dmitry A. Leontiev e Andréa M. Longarezi.

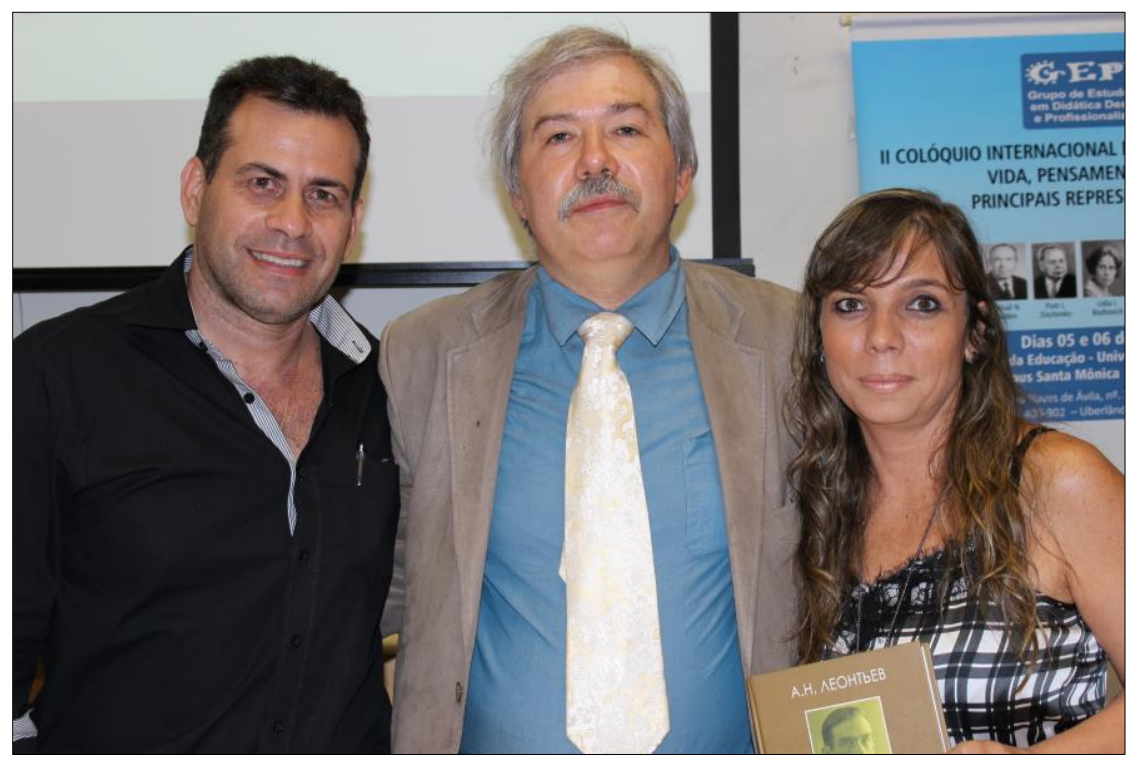

Fonte: Arquivo do GEPEDI.

ANDRÉA M. LONGAREZI E ROBERTO V. PUENTES: Agradecemos sua disponibilidade para dialogar sobre as tensões teóricas que emergem no seio das 
perspectivas que compõem o corpo da teoria histórico-cultural. O GEPEDI, enquanto grupo de pesquisa, tem se dedicado a tornar pública as obras dos vários autores e grupos que, com pontos de convergências e divergências, compuseram esse corpus teórico. Nesse mesmo sentido, o trabalho que temos realizado tem ta mbém a finalidade de dar espaço para que as nuances, debates e embates nessa perspectiva se façam explícitas, de modo a que possamos avançar na compreensão da complexa e diversa teoria que a psicologia assumiu. Obrigada!!

DMITRY A. LEONTIEV: As perguntas são muito boas. Acho que o mundo mudou muito, inclusive na psicologia, e, nas ultimas dezenas de anos, décadas, aconteceu um processo de, cada vez mais, apagarem-se as fronteiras entre as diferentes escolas e a construção da formação, aos poucos, de uma língua praticamente única na ciência e se unificou aos poucos os critérios das avaliações. Hoje em dia, ninguém mais pergunta de qual escola você é, mas quais problemas você consegue solucionar a partir das suas ideias. E hoje, na minha opinião. não faz mais tanto sentido a pureza das ideias de qualquer uma das escolas teóricas, inclusive a da atividade. As escolas e as correntes teóricas estão agindo de maneira colaborativa entre si.

Eu discuto sobre esse tema com meus colegas porque muitos estão acostumados a trabalharem no âmbito da escola da atividade, por exemplo, e têm dificuldade de cooperar com outras escolas ao redor do mundo. Mas, isso é passado. E digo muito que a psicologia da atividade é um prato saboroso que você tem que saber preparar muito bem para apreciar; e tem também um jeito que ele fica totalmente intragável, é quando você o faz no próprio caldo!

ANDRÉA M. LONGAREZI E ROBERTO V. PUENTES: O motivo principal do diálogo sobre o tema está justamente no embate das várias correntes e no entendimento de que as diferentes interpretações sobre esses embates precisam compor o cenário dos estudos na área. Mais uma vez, obrigada. 
DMITRY A. LEONTIEV: Também sou grato e aprecio muito esse grande trabalho que vocês estão fazendo, é fantástico e estou pronto, na medida das minhas possibilidades, para ajudar como puder.

Figura 4: Dmitry A. Leontiev presenteando o GEPEDI com um dos livros que organizou com os escritos de seu avô A. N. Leontiev.

(da esquerda para direita: Roberto V. Puentes, Dmitry A. Leontiev e Andréa M. Longarezi).

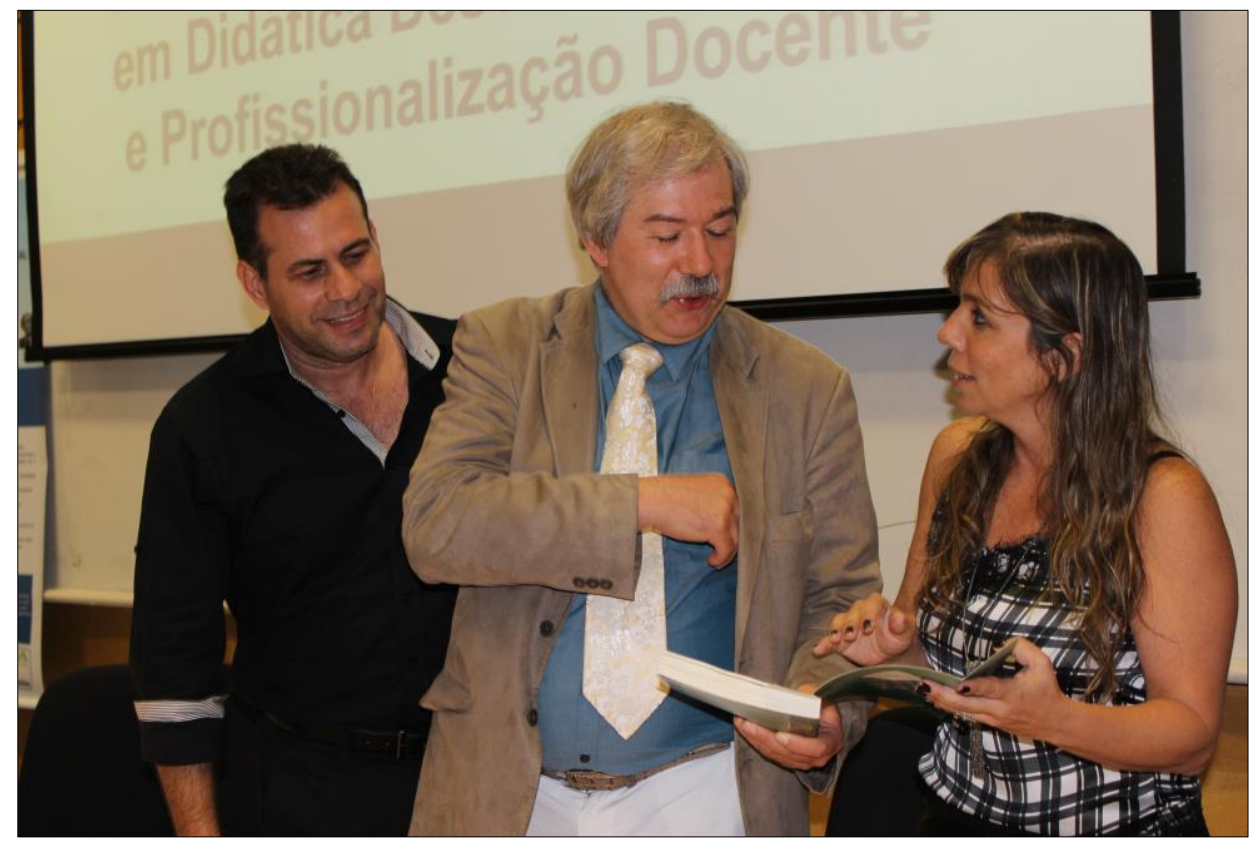

Fonte: Arquivo do GEPEDI.

\section{REFERÊNCIAS}

LEONTIEV, Alexis N. O desenvolvimento do psiquismo. Lisboa: Horizonte Universitário. 1978.

LEONTIEV, Alexis N. Actividad, conciencia y personalidad. Habana: Editorial Pueblo y Educación. 1983.

LEONTIEV, Alexis N. Sobre la teoría del desarrollo de la psique del niño. In: Antología de la psicología pedagógica y de las edades. I.I.IIiasov; V. Ya. Liaudis. Título original de la obra: Jrestomatia pi vosrastmai i pedagoguicheskei. Traducción: Carmen Rodrigues Garcia. Editorial Pueblo y Educación, 1986a, p.10-13.

LEONTIEV, Alexis N. Sobre la formación de las capacidades. In: Antología de la psicología pedagógica y de las edades. I.I.IIiasov; V. Ya. Liaudis. Título original de la obra: Jrestomatia pi vosrastmai i pedagoguicheskei. Traducción: Carmen Rodrigues García. Editorial Pueblo y Educación,1986b, p.44-54. 
LEONTIEV, Alexis N La comprensión del significado por parte del portador de la lengua. In: Antología de la psicología pedagógica y de las edades. I.I.Iliasov; V. Ya. Liaudis. Título original de la obra: Jrestomatia pi vosrastmai i pedagoguicheskei. Traducción: Carmen Rodrigues Garcia. Editorial Pueblo y Educación,1986c, p.260-265.

LEONTIEV, Alexis N.; El enfoque histórico em el estudio de la psiquis del hombre. In: PUZIREI, Andrei; GUIPPENREITER, Yulia - El proceso de formación de La psicología marxista Editorial Progreso. Moscú, 1989a. Traducido Del russo por Marta Shuare. ISBN 5-0-001254-5.

LEONTIEV, Alexis N. El problema de la actividad em la psicología. In: In: PUZIREI, Andrei; GUIPPENREITER, Yulia - El proceso de formación de La psicología marxista Editorial Progreso. Moscú, 1989b. Traducido del ruso por Marta Shuare. ISBN 5-0-001254-5.

LEONTIEV, Alexis. N. Acerca de la importancia del concepto de actividad objetal para la psicología. In: ROJAS, Luis Quintanar. (compilador) La formación da las funciones psicológicas durante el desarrollo del niño. Universidad Autónoma de Tlaxcala. México. Segunda reimpresión: 2001. Traducción del ruso: Yulia V. Solovieva.

LEONTIEV, Alexis N. Uma contribuição para o desenvolvimento da psique infantil. In: VIGOTSKI, L. S., LURIA, A. R.; LEONTIEV, A. N. Linguagem, desenvolvimento e aprendizagem. $10^{\mathrm{a}}$ ed. São Paulo: Ícone, 2006.

LEONTIEV, Alexis N. As necessidades e os motivos da atividade. In: LONGAREZI, A.M.; PUENTES, R.V. Ensino Desenvolvimental. Antologia I, Uberlândia: Edufu, 2017, p. 39-58. DOI: https://doi.org/10.14393/edufu-978-85-7078-433-9.

LEONTIEV, Dmitry A. Joint Activity, Communication, and Interaction (Toward Wellgrounded "Pedagogy of Cooperation"), Journal of Russian \& East European Psychology, Vol. 30, n.2, 1992, 43-58. DOI: https://doi.org/10.2753/rpo1061-0405300243.

LEONTIEV, Dmitry A. Three Facets of Meaning. Journal of Russian and East European Psychology, vol. 43, no. 6, November-December 2005, p. 45-72. DOI: https://doi.org/10.1080/10610405.2005.11059270.

LEONTIEV, Dmitry A. Questões de educação e psicologia pedagógica nas obras de A. A. Leontiev (2015). In: PUENTES, Roberto V.; LONGAREZI, Andréa M. (Orgs.). Ensino Desenvolvimental: vida, pensamento e obra dos principais representantes russos. Livro II. Uberlândia. Edufu. 2017. Disponível em: http://www.edufu.ufu.br/sites/edufu.ufu.br/files/ebook_ensino_desenvolvimental_livro_ii_2015_0.pdf. Acesso em: 30.05.2019. DOI: https://doi.org/10.14393/edufu-978-85-7078-409-4.

LONGAREZI, Andréa M. Prefácio. PUENTES, Roberto V.; CARDOSO, Cecília G. C.; AMORIM, Paula A. P. (Orgs.). Teoria da atividade de estudo: contribuições de Daniil Borisovich Elkonin, VasiliVasilovich Davidov e Vladimir Vladimirovich Repkin. 1. ed. Curitiba: CRV, 2019a. 
LONGAREZI, Andréa M. Significado, sentido e Atividade de Estudo: uma problematização dos motivos na estrutura da atividade. GUADALUPE, Sueli. (Org.) Significado e sentido na educação para a humanização. Marília: UNESP, 2019b. DOI: https://doi.org/10.36311/2019.978-85-7249-036-8.

LONGAREZI, Andréa M. Gênese e constituição da Obutchénie Desenvolvimental: expressão da produção singular-particular-universal enquanto campo de tensão contraditória. Revista Educação (Santa Maria online), v. 45, p. 1-32, 2020a. Disponível em: https://periodicos.ufsm.br/reveducacao/article/view/48103\#: :text=Apreender\%20a\%20gener alidade\%20e\%20a,do\%20singular\%2Dparticular\%2Duniversal. DOI: https://doi.org/10.5902/1984644448103.

LONGAREZI, Andréa M. Didática desenvolvimental: um olhar para sua gênese na tradição da teoria histórico-cultural e possíveis desdobramentos para a realidade brasileira. In: FRANCO, Adriana de F.; TULESKI, Silvana C.; MENDONÇA, Fernando. (Org.). Ser ou não ser na sociedade capitalista: o materialismo histórico-dialético como método da Psicologia Histórico-Cultural e da Teoria da determinação social dos processos de saúde e doença. 1ed.Goiânia: Editora Phillos, 2020b, v. 1, p. 54-87.

LONGAREZI, Andréa M.; FRANCO, Patrícia L. J. A.N. Leontiev: a vida e a obra do psicólogo da atividade. In: LONGAREZI, Andréa M.; PUENTES, Roberto V. (Orgs.). Ensino Desenvolvimental: vida, pensamento e obra dos principais representantes russos. Livro I. Uberlândia. Edufu. 2013. DOI: https://doi.org/10.14393/edufu-978-85-7078-491-9.

LONGAREZI, Andréa M, FRANCO, Patrícia J. L. A.Н. Леонтьев: жизнь и деятельность психолога (Vida e obra do psicólogo da Atividade). Дубненский психологический журнал (Jornal de Psicologia de Dubna), Dubna/Rússia, n.1, 2015.

PUENTES, Roberto V. Didática desenvolvimental da atividade: o sistema ElkoninDavidov (1958-2015) Obutchénie. Revista de Didática e Psicologia Pedagógica. GEPEDI/ Uberlândia: EDUFU, 2017, vol. 1. n.1, p. 20-58. Disponível em: http://www.seer.ufu.br/index.php/Obutchenie/article/view/38113/21567. Acesso em: 06/07/2018. DOI: https://doi.org/10.14393/OBv1n1a2017-2.

PUENTES, Roberto V.; LONGAREZI, Andréa M. A Didática Desenvolvimental: seu campo conceitual na tradição da psicologia histórico-cultural da Atividade. In: LONGAREZI, Andréa M.; PUENTES, Roberto V. (Orgs.). Fundamentos psicológicos e didáticos do Ensino Desenvolvimental. Uberlândia: EDUFU, 2017a.

PUENTES, Roberto V.; LONGAREZI, Andréa M. Didática desenvolvimental: sessenta anos de tradição teórica, epistemológica e metodológica. Obutchénie. Revista de Didática e Psicologia Pedagógica. GEPEDI/ Uberlândia: EDUFU, 2017b, vol. 1. n.1, p. 9-19. Disponível em: http:/www.seer.ufu.br/index.php/Obutchenie/article/view/38417/22696. Acesso em: 06/07/2018. DOI: https://doi.org/10.14393/OBv1n1a2017-1. 